\title{
Aluminum Strand Coating for Increasing the Interstrand Contact Resistance in Rutherford Type Superconducting Cables
}

\author{
Christian Scheuerlein, Gerard Willering, Arjan Verweij, Angelo Bonasia, Luc Oberli, Mauro Taborelli, and \\ Raimond Richter
}

\begin{abstract}
The interstrand contact resistance $\left(R_{c}\right)$ in Rutherford type cables for fast cycling superconducting magnets must be sufficiently high in order to limit eddy current losses. The required value for $R_{\mathrm{c}}$ depends on the cable and magnet geometries and on the foreseen cycling rate, but is typically of the order of one $\mathrm{m} \Omega$. Such values can be reached with a dedicated strand coating or with a resistive internal cable barrier. As a possible candidate Al strand coatings have been tested. For a Rutherford type inner conductor cable of the Large Hadron Collider (LHC) made of Al coated strands $R_{c}$ values higher than $500 \mu \Omega$ are achieved. The native $\mathrm{Al}_{2} \mathrm{O}_{3}$ oxide layer formed at ambient temperature in air is sufficient to reach this high contact resistance. A $6 \mathrm{~h}-200^{\circ} \mathrm{C}$ oxidation heat treatment in air with $100 \%$ relative humidity further increases $R_{C}$ to values above $600 \mu \Omega$. Due to the high thermal and mechanical stability of $\mathrm{Al}_{2} \mathrm{O}_{3}$ only a relatively moderate $R_{c}$ drop of about $40 \%$ is obtained during a $190^{\circ} \mathrm{C}$ heat treatment under 50 MPa pressure (the so-called curing cycle of the coil insulation) subsequent to the $6 \mathrm{~h}-200^{\circ} \mathrm{C}$ oxidation heat treatment.
\end{abstract}

Index Terms-Contact resistance, superconducting cables.

\section{INTRODUCTION}

$\mathbf{T}$ HE contact resistance of the crossing strands in Rutherford type cables for high field magnets must be controlled in order to reduce coupling currents between the strands and at the same time allow sufficient current sharing for the superconductor stability [1]. $R_{c}$ within the cables of the LHC main magnets, as an example, should be between 20 and $100 \mu \Omega$ at operating conditions. Eddy current effects, i.e. losses and field harmonics, are proportional to $\mathrm{dB} / \mathrm{dt}$ and, therefore, for future fast cycling magnets $R_{c}$ values must be strongly increased with respect to the $R_{c}$ values obtained with the standard LHC cables.

In order to achieve the needed $R_{c}$ values in the LHC superconducting cables a $\mathrm{Sn}_{95}$ wt. $\mathrm{Ag}_{5}$ wt. coating is deposited onto the copper matrix of the strands by a continuous hot dip process. Subsequently the cable made of $\mathrm{Sn}_{95 \mathrm{wt}} \mathrm{Ag}_{5}$ wt. coated strands is submitted to a $200^{\circ} \mathrm{C}$ heat-treatment (HT) in air, lasting typically a few hours [1], [2]. In this case the contact resistance increase is due to the $\mathrm{Cu}_{2} \mathrm{O}$ oxide layer that remains on top of

Manuscript received August 28, 2008. First published June 30, 2009; current version published July 15, 2009.

C. Scheuerlein, G. Willering, A. Verweij, A. Bonasia, L. Oberli, and M. Taborelli are with CERN, Accelerator Technology Department, $\mathrm{CH}-1211$ Geneva 23, Switzerland (e-mail: Christian.Scheuerlein@cern.ch).

R. Richter is with RASANT-ALCOTEC Beschichtungstechnik GmbH, Overath, Germany.

Color versions of one or more of the figures in this paper are available online at http://ieeexplore.ieee.org.

Digital Object Identifier 10.1109/TASC.2009.2019291 a $\mathrm{Cu}_{3} \mathrm{Sn}$ intermetallic layer that is formed on the strand during the $200^{\circ} \mathrm{C}$ HT in air [3], [4].

Unlike most native metal oxides, the air formed $\mathrm{Al}$ oxide, $\mathrm{Al}_{2} \mathrm{O}_{3}$, is a good electrical insulator, whose electrical resistivity is several orders of magnitude higher than for instance that of the native $\mathrm{Cu}$-oxide, which is a semi-conductor. Thus, it should be expected that $\mathrm{Al}$ coated strands exhibit a comparatively high contact resistance, even without any high temperature HT in oxidizing atmospheres. Al oxide films also exhibit good mechanical and thermal stability and are widely used for protection against wear and corrosion [5]. In this article we present for the first time $R_{c}$ measurements on a LHC inner conductor cable made from strands that have been coated with a $0.5 \mu \mathrm{m}$ thick Al layer. $R_{c}$ results are compared with those obtained for cables made of strands with various strand coatings that have been previously measured at CERN under similar experimental conditions.

\section{EXPERIMENTAL}

\section{A. The Samples}

The $\mathrm{Al}$ coating has been applied onto the $\mathrm{Cu}$ matrix of a LHC type $01 \mathrm{Nb}-\mathrm{Ti} / \mathrm{Cu}$ composite strand with a nominal diameter of $1.065 \mathrm{~mm}$ and a length of $40 \mathrm{~m}$. The $\mathrm{Al}$ coating is deposited by an electrochemical process. This process is based on metal deposition from an organometallic complex electrolyte, which consists essentially of $\mathrm{Al}$ alkyl complexes in a nonaqueous solution. All process steps are performed within a closed unit under inert gas atmosphere, which assures excellent $\mathrm{Al}$ coating adhesion to the substrate.

The thickness of the galvano-aluminum coatings can be varied over a large range. The coating thickness on the strands used for the fabrication of Rutherford type cable studied here is $0.5 \mu \mathrm{m}$. In order to obtain entirely non porous films, a minimum thickness of about $7 \mu \mathrm{m}$ is needed. The Vickers hardness reported for a $30 \mu \mathrm{m}$ thick galvano $\mathrm{Al}$ coating is $\mathrm{HV}_{0.015}=20$. The coatings have a very high ductility and no crack formation in the $\mathrm{Al}$ due to the plastic deformation during cabling is expected to occur. More information about the galvano $\mathrm{Al}$ coatings can be found in reference [6].

Pure $\mathrm{Al}$ is a good electrical conductor. By conversion of the $\mathrm{Al}$ into the $\mathrm{Al}$ oxide $\mathrm{Al}_{2} \mathrm{O}_{3}$ an insulating layer can be obtained. This can be achieved for instance by oxidation in air or other oxidizing atmospheres at room or high temperatures. For Al coatings that are thick enough, anodic oxidation can be applied to increase the $\mathrm{Al}_{2} \mathrm{O}_{3}$ layer thickness. The samples used in the 


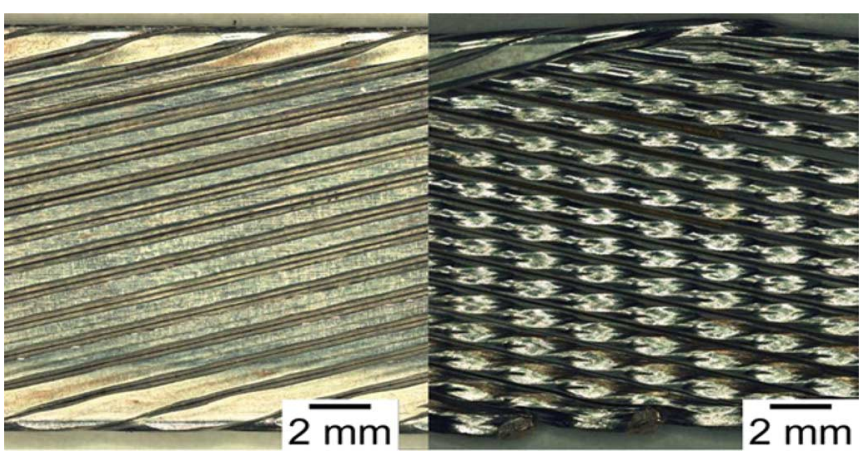

Fig. 1. Inner LHC superconductor cable, consisting of $28 \mathrm{Nb}-\mathrm{Ti} / \mathrm{Cu}$ strands with a nominal diameter of $1.065 \mathrm{~mm}$. The right image shows the cross contacts inside the cable made of $\mathrm{Al}$ coated strands.

present study were either oxidized at room temperature in ambient air, or at $200^{\circ} \mathrm{C}$ in air with $100 \%$ relative humidity.

A LHC inner conductor cable has been fabricated at CERN from the Al coated strands (see Fig. 1). The Rutherford type cable, made out of 28 strands, has a mid thickness of $1.9 \mathrm{~mm}$, a width of $15 \mathrm{~mm}$, a keystone angle of $1.25^{\circ}$ and a transposition pitch of about $115 \mathrm{~mm}$. The cable compaction factor is about 90\%. Due to the cable key stone angle the cross contact areas increase from the thick cable edge (top) towards the thin edge (bottom).

\section{B. $R_{c}$ Measurements}

Throughout this article the interstrand contact resistance $\left(R_{c}\right)$ is defined as the resistance of one cross-over of two strands in the Rutherford cable. $R_{c}$ is measured at $4.2 \mathrm{~K}$ under a pressure of $50 \mathrm{MPa}$ applied to the broad face of the cable sample. As can be seen in Fig. 1, the interstrand cross contact areas vary across the cable width from about $0.7 \mathrm{~mm}^{2}$ to $1.5 \mathrm{~mm}^{2}$ from the thick to the thin cable edge, respectively. The $R_{c}$ results presented are average values obtained for cross contacts distributed over the whole cable width. $R_{c}$ measurements have been performed on as-received cable samples and after a $0.5 \mathrm{~h}-190^{\circ} \mathrm{C}$ cable HT under $50 \mathrm{MPa}$ pressure. This HT simulates the influence of the coil curing in superconducting magnets on $R_{c}$. More details about the $R_{c}$ measurement method can be found in [2].

In the present study $R_{c}$ of an inner (01 type) LHC cable has been measured. From previous experience it is known that $R_{c}$ of (02 type) LHC outer conductor cables, made of 36 strands with a nominal diameter of $0.825 \mathrm{~mm}$, is more than twice the $R_{c}$ measured for 01 cables with identical coating and oxidation HT. The resistance of adjacent contacts $\left(R_{a}\right)$ cannot be measured with the used experimental set-up. As a rough estimate it may be assumed that $R_{a}$ is about 8 times higher than $R_{c}$ [7].

\section{Surface Analysis by X-Ray Photoelectron Spectroscopy}

The surfaces of the Al coated strands after different HT have been analysed by X-ray Photoelectron Spectroscopy (XPS). The characteristic electrons that are detected by XPS are emitted from the topmost some $10 \mathrm{~nm}$ of the surface analysed. In addition to the identification of the surface elements, XPS also yields chemical specificity, provided that photoelectron peak shifts are accurately measured and compensated for sample charging effects.
TABLE I

$R_{c}$ Measured for LHC Type 01 Cables Made of Al Coated Strands. MEASUREMENTS HAVE BEEN PERFORMEd ON AS-RECEIVEd CABle SAMPLES AND AFTER A $6 \mathrm{~h}-200^{\circ} \mathrm{C}$ HT IN AIR WITH $100 \%$ REL. HUMIDITY. EACH HT WAS FOLlOWED BY A SO-CALLED CURING HT $\left(0.5\right.$ h- $190^{\circ} \mathrm{C}$ HT UNDER 50 $\mathrm{MPa})$

\begin{tabular}{cccc}
\hline \hline No HT & After curing & $\begin{array}{c}\mathbf{6 ~ h - 2 0 0}^{\circ} \mathbf{C}, \mathbf{1 0 0 \%} \\
\text { rel. humidity }\end{array}$ & After curing \\
\hline $528 \pm 265 \mu \Omega$ & $\begin{array}{c}87 \pm 53 \mu \Omega \\
(-83 \%)\end{array}$ & $640 \pm 223 \mu \Omega$ & $\begin{array}{c}377 \pm 141 \mu \Omega \\
(-41 \%)\end{array}$ \\
\hline \hline
\end{tabular}

XPS measurements are performed using an ESCA 5400 series instrument from Physical Electronics. For the acquisition of survey and high resolution spectra the PHI model 10-360 spherical capacitor electron spectrometer is operated with a fixed pass energy of $89 \mathrm{eV}$ and $35 \mathrm{eV}$, respectively. A non-monochromated $\mathrm{Mg} \mathrm{K} \mathrm{K}_{\alpha} \mathrm{X}$-ray source $(h v=1253.6 \mathrm{eV})$ is used to excite photoelectrons. Prior to the measurements, the binding energy (BE) scale has been calibrated using in-situ sputter-cleaned $\mathrm{Au}$ and $\mathrm{Cu}$ samples.

\section{RESULTS}

\section{A. Contact Resistance Measurement Results}

$R_{c}$ measurements have been performed using cable samples as received after cabling (no HT) and after different $200^{\circ} \mathrm{C}$ heat treatments. $200^{\circ} \mathrm{C}$ heat treatments in ordinary laboratory air have been found to have only a minor influence on $R_{c}$. Temperatures exceeding $200^{\circ} \mathrm{C}$ are not compatible with $\mathrm{Nb}$-Ti strands, since they would cause a degradation of the critical superconductor properties. Therefore, a $200^{\circ} \mathrm{C}$ HT has been performed in air with $100 \%$ relative humidity.

The $R_{c}$ results are summarized in Table I. The standard deviation indicates the scatter of the different $R_{c}$ measurement results that have been obtained for the different cable samples. During a HT lasting $6 \mathrm{~h}$ at $200^{\circ} \mathrm{C}$ in air with $100 \%$ rel. humidity, $R_{c}$ increases to about $640 \mu \Omega$, which is about $25 \%$ higher than the $R_{c}$ of the as-received cable. In order to simulate the influence of the so-called curing HT of magnet coils, after each $R_{c}$ measurement the cable is submitted to a $0.5 \mathrm{~h}-190^{\circ} \mathrm{C} \mathrm{HT}$ at $50 \mathrm{MPa}$ pressure and afterwards $R_{c}$ is re-measured again. During the curing HT $R_{c}$ is reduced by about $40 \%$.

\section{B. Surface Analysis Results}

Due to the high $\mathrm{Al}_{2} \mathrm{O}_{3}$ resistivity the strand sample surface is electrically charged during the measurements and the photoelectron peaks are shifted by about $5 \mathrm{eV}$. For charge compensation the $\mathrm{C} 1 \mathrm{~s}$ peak position of adventitious carbon is used as a reference.

Survey and $\mathrm{Al} 2 \mathrm{p}$ high resolution photoelectron spectra are presented in Fig. 2 for a strand heat treated at $200^{\circ} \mathrm{C}$ in air with $100 \%$ relative humidity. Some metallic signal is still detected through the $\mathrm{Al}$ oxide layer, indicating that the $\mathrm{Al}_{2} \mathrm{O}_{3}$, thickness does not exceed $10 \mathrm{~nm}$ (the attenuation length of the $\mathrm{Al} 2 \mathrm{p}$ photoelectrons is about $2.5 \mathrm{~nm}$ [8]).

As can be seen in the high resolution spectrum, the detected $\mathrm{Al}$ is mainly in the form of $\mathrm{Al}_{2} \mathrm{O}_{3}$. Traces of $\mathrm{Cu}$ are also detected, indicating some porosity of the coating. A rough esti- 

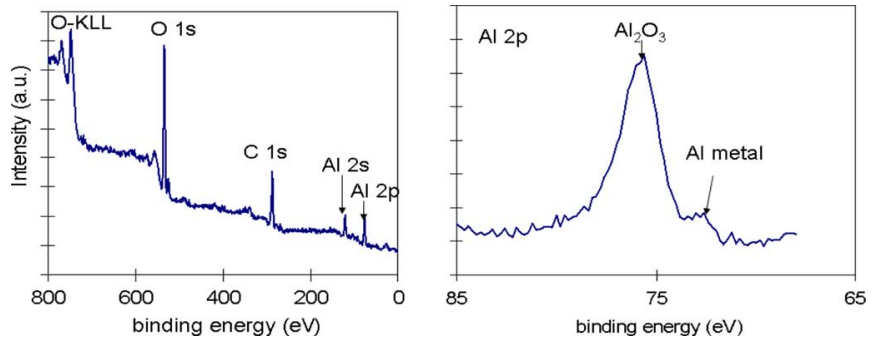

Fig. 2. XPS survey spectrum (left) and $\mathrm{Al} 2 \mathrm{p}$ high resolution spectrum (right) acquired for the Al coated strand extracted from the LHC 01 cable after 6 $\mathrm{h}-200^{\circ} \mathrm{C}$ HT in $100 \%$ relative humidity.

TABLE II

INTERSTRAND CONTACT RESISTANCE IN TYPE 01 LHC CABLES WITH DiFFERENT COATINGS. THE FOLLOWING OXIDIZING HEAT TREATMENTS IN AiR HAVE BEEN PERFORMED: * 5 min $-200^{\circ} \mathrm{C},{ }^{*} * 30 \mathrm{~min}-190^{\circ} \mathrm{C}, * * * 6 \mathrm{~h} 200^{\circ} \mathrm{C}$ $100 \%$ REL. HUMIDITY

\begin{tabular}{lllll}
\hline \hline & $\begin{array}{l}\text { As } \\
\text { received }\end{array}$ & $\begin{array}{l}\text { After } \\
\text { curing }\end{array}$ & $\begin{array}{l}\text { HT in air } \\
(*, * *, * * *)\end{array}$ & $\begin{array}{l}\text { After HT } \\
\text { + curing }\end{array}$ \\
\hline Al & $530 \mu \Omega$ & $90 \mu \Omega$ & $640 \mu \Omega * * *$ & $380 \mu \Omega$ \\
Sn95-Ag5 [2,9] & $1.7-30 \mu \Omega$ & $0.5-4.5 \mu \Omega$ & $100-200 \mu \Omega$ & $17-23 \mu \Omega$ \\
Bare Cu [2] & $80-700 \mu \Omega$ & $0.5-1.6 \mu \Omega$ & - & - \\
Ni [2] & $320 \mu \Omega$ & $55 \mu \Omega$ & $>300 \mu \Omega * *$ & - \\
Sn65-Ni35 [1] & $65 \mu \Omega$ & $12 \mu \Omega$ & - & - \\
Cu55-Sn45 [1] & $90 \mu \Omega$ & $2.2 \mu \Omega$ & $600 \mu \Omega *$ & $130 \mu \Omega$ \\
\hline \hline
\end{tabular}

mate of the $\mathrm{Al}_{2} \mathrm{O}_{3}$ oxide thickness can also be obtained by combined electron spectroscopy and sputter depth profiling measurements, assuming that the sputtering speed for $\mathrm{Al}_{2} \mathrm{O}_{3}$ is identical to that of the reference material $\mathrm{Ta}_{2} \mathrm{O}_{5}$. $\mathrm{An}_{2} \mathrm{Al}_{2} \mathrm{O}_{3}$ thickness of about $9 \mathrm{~nm}\left(\mathrm{Ta}_{2} \mathrm{O}_{5}\right.$ equivalent) has been measured after a $10 \mathrm{~h}-200^{\circ} \mathrm{C} \mathrm{HT}$ in ordinary laboratory air.

\section{DisCuSSION AND CONCLUSION}

The $R_{c}$ of Rutherford type cables can be strongly increased when the strands are coated with a thin $\mathrm{Al}$ layer instead of the LHC type $\mathrm{Sn}-\mathrm{Ag}$ layer. The relatively thin $\mathrm{Al}_{2} \mathrm{O}_{3}$ layer formed in air at ambient temperature is sufficient to achieve a contact resistance above $500 \mu \Omega$.

$200^{\circ} \mathrm{C}$ heat treatments in air with $100 \%$ relative humidity can further increase $R_{c}$. The $\mathrm{Al}_{2} \mathrm{O}_{3}$ thickness after this treatment is about $10 \mathrm{~nm}$. In Table II, $R_{c}$ values obtained for the Al coated LHC type 01 cable are compared with $R_{c}$ of type $01 \mathrm{Nb}$-Ti cables with other coatings that have been measured under similar experimental conditions at CERN. All cable samples were first measured "as received" and after subsequent $0.5 \mathrm{~h}-190^{\circ} \mathrm{C}$ HT under a pressure of $50 \mathrm{MPa}$ (so-called curing $\mathrm{HT}$ ). $R_{c}$ of some cable samples was also measured after HT in air and again after subsequent $0.5 \mathrm{~h}-190^{\circ} \mathrm{C} \mathrm{HT}$ under a pressure of $50 \mathrm{MPa}$.

It can be seen that the $\mathrm{Al}$ coated cable exhibits a relatively high $R_{c}$ and that the curing treatment has a relatively small influence on $R_{c}$ of the $\mathrm{Al}$ coated cable. This can be explained by the high mechanical and thermal stability of $\mathrm{Al}_{2} \mathrm{O}_{3}$ as compared to other native metal oxides.

$R_{c}$ of identically treated cables increases with decreasing strand diameter. As an example, for LHC type 02 cables (strand diameter $0.825 \mathrm{~mm}$ ) it is estimated that $R_{c}$ is at least twice that of $R_{c}$ of type 01 cables after identical HT. Thus, for cables made of smaller Al coated strands, the high contact resistance that is needed in order to limit eddy current losses in fast cycling magnets may be provided.

The ductile galvano-aluminum coatings are well adhesive to the $\mathrm{Cu}$ strand matrix and have a uniform thickness, which can be controlled in tight tolerances. Unlike other coatings like $\mathrm{Cr}$ or $\mathrm{Ni}$ that can be used to increase the contact resistance in superconducting cables, $\mathrm{Al}$ coatings are very soft, which facilitates the production of Rutherford type cables.

The thermal-electromagnetic stability of a LHC type 01 cable made of $\mathrm{Al}$ coated strands against local heat depositions has been tested at the FRESCA test facility at CERN and evaluation of these results is underway.

\section{ACKNOWLEDGMENT}

The authors thank D. Richter from CERN for the $R_{c}$ measurements.

\section{REFERENCES}

[1] D. Richter, J. D. Adam, D. Leroy, and L. R. Oberli, "Strand coating for the superconducting cables of the LHC main magnets," IEEE Trans. Appl. Supercond., vol. 9, no. 2, pp. 735-739, 1999.

[2] D. Richter, J. D. Adam, J.-M. Depond, D. Leroy, and L. R. Oberli, "DC measurement of electrical contacts between strands in superconducting cables for the LHC main magnets," IEEE Trans. Appl. Supercond., vol. 7, no. 2, pp. 786-792, 1997.

[3] C. Scheuerlein, P. Gasser, P. Jacob, D. Leroy, L. Oberli, and M. Taborelli, "The effect of CuSn intermetallics on the interstrand contact resistance in LHC superconducting cables," J. Appl. Phys., vol. 97, no. 3, 2005.

[4] C. Scheuerlein, M. Taborelli, and M. Cantoni, "Oxidation and contact resistance of Sn-Ag coated superconducting strands for the LHC,' Appl. Surf. Sci, vol. 253, no. 3, pp. 1393-1398, 2006.

[5] L. P. H. Jeurgens, W. G. Sloof, F. D. Tichelaar, and E. J. Mittemeijer, "Growth kinetics and mechanisms of aluminium-oxide films formed by thermal oxidation of aluminium," J. Appl. Phys., vol. 92, no. 3, pp. 1649-1656, 2002.

[6] R. Richter, "Optimierter Beschichtungsprozess-Direkte Aluminierung ohne Zwischenschicht," Journal für Oberflächentechnik, Nr.: 2007-07, 2007.

[7] R. Otmani, A. Devred, and P. Tixador, "Interstrand and AC-loss measurements on Rutherford-type cables for accelerator magnet applications," IEEE Trans. Appl. Supercond., vol. 11, no. 1, pp. 2760-2763, 2001.

[8] P. J. Cumpson and M. Seah, Surface and Interface Analysis, vol. 25, p. 430, 1997.

[9] D. Leroy, "Review of the R\&D and supply of the LHC superconducting cables," IEEE Trans. Appl. Supercond., vol. 16, no. 2, pp. 1152-1159, 2006. 